ARTICLE OPEN

\title{
Sea-spray regulates sulfate cloud droplet activation over
}

\section{oceans}

\author{
Kirsten N. Fossum (iD) ${ }^{1}$, Jurgita Ovadnevaite $\mathbb{D}^{1}{ }^{1}$, Darius Ceburnis $\mathbb{D}^{1}$, Jana Preißler ${ }^{1}$, Jefferson R. Snider (iD ${ }^{2}$, Ru-Jin Huang ${ }^{1,3,4}$, \\ Andreas Zuend (iD) $)^{5}$ and Colin O'Dowd (iD ${ }^{1 \times}$
}

Sulfate aerosols are typically the dominant source of cloud condensation nuclei (CCN) over remote oceans and their abundance is thought to be the dominating factor in determining oceanic cloud brightness. Their activation into cloud droplets depends on dynamics (i.e. vertical updrafts) and competition with other potential CCN sources for the condensing water. We present new experimental results from the remote Southern Ocean illustrating that, for a given updraft, the peak supersaturation reached in cloud, and consequently the number of droplets activated on sulfate nuclei, is strongly but inversely proportional to the concentration of sea-salt activated despite a 10-fold lower abundance. Greater sea-spray nuclei availability mostly suppresses sulfate aerosol activation leading to an overall decrease in cloud droplet concentrations; however, for high vertical updrafts and low sulfate aerosol availability, increased sea-spray can augment cloud droplet concentrations. This newly identified effect where seasalt nuclei indirectly controls sulfate nuclei activation into cloud droplets could potentially lead to changes in the albedo of marine boundary layer clouds by as much as $30 \%$.

npj Climate and Atmospheric Science (2020)3:14; https://doi.org/10.1038/s41612-020-0116-2

\section{INTRODUCTION}

It has long been considered that increasing the abundance of cloud condensation nuclei (CCN) in optically thin clouds would lead to increased reflectance at cloud top (the 1st indirect aerosol radiative effect) ${ }^{1}$, and extended lifetime due to delays in precipitation onset (the 2 nd indirect aerosol radiative effect) ${ }^{2}$. Both effects lead to an increase in planetary albedo, thereby partly offsetting warming caused by an accumulation of greenhouse gases in the atmosphere. Because of their high susceptibility, and the high sunlight absorption of the underlying oceanic surface, marine clouds are thought to be particularly important contributors to the aerosol-cloud-radiation cooling effect-for example, a $20-35 \%$ increase in low-level cloud amount could offset a doubling of $\mathrm{CO}_{2}{ }^{3-5}$. The potential role of marine clouds in regulating climate led to suggestions of various feedback cycles involving both primary (i.e. bubble-mediated sea-spray) marine aerosol production ${ }^{6}$ and secondary (gas-to-particle) marine aerosol production ${ }^{7}$. For primary production of sea-salt, it was suggested that zonal wind speeds would increase with rising global temperatures, leading to increased sea-salt fluxes to the atmosphere ${ }^{6}$; while plankton activity was suggested to increase with rising temperatures, leading to increased emissions of biogenic sulfur gases from the ocean surface, increasing sulfate aerosol formation, ultimately increasing the availability of $\mathrm{CCN}^{7}$.

In general, an increased number concentration of CCN within a cloud-topped boundary layer leads to increased cloud droplet number concentration (CDNC), and assuming the cloud liquid content is unchanged, to increased cloud albedo. Exploitation of this in geoengineering proposals involves regional-scale addition of sea-salt particles, in the range $0.8-4 \mu \mathrm{m}$ diameter ${ }^{8-10}$, to mitigate global warming. However, such connections would require a monotonic relationship between sub-cloud CCN and CDNC which may not always be the case ${ }^{11,12}$.

Primary sea-salt and secondary sulfate aerosol can also become enriched in organics under conditions of high biological activity ${ }^{13}$, leading to quite complicated changes in the cloud droplet activation properties. This is due to the diverse effects that organics can have on water uptake, which can inhibit or augment droplet activation at a given supersaturation depending on the nature of the inorganic-organic chemical mixture ${ }^{14,15}$

Approaches to quantify the less complex scenario of the relative contribution of sulfate and sea-salt to CCN have typically concluded that non-sea-salt sulfate (nss- $\mathrm{SO}_{4}^{2-}$ ) dominates marine boundary layer CCN at higher supersaturations while sea-salt dominates at low supersaturations ${ }^{16-19}$. In this study, we aim to not only quantify the first order effect of sea-salt addition (or subtraction) to a sulfate-rich CCN population, but also to elucidate any possible higher order effects such as modification of the supersaturation which can indirectly impact on the sulfate CCN concentration.

In doing so, we apply a relatively novel technique to a suite of measurements and associated analysis of marine aerosol physicochemical and CCN characteristics in the clean Southern Ocean/ sub-Antarctic marine environment to quantify the number of seasalt and sulfate activated cloud droplets (as opposed to CCN spectra). CCN measurements are central to the analysis, as the data gathered are used to generate critical supersaturation $\left(S_{c}\right)$ versus critical dry diameter of activation $\left(D_{c}\right)$ curves (or $S_{c}-D_{c}$ curves) of the ambient marine air. Our data analysis, centred on the $S_{c}-D_{c}$ curves, builds on the well-justified assumption that, in the absence of clouds, the initial size distribution of submicron secondary marine aerosol is monomodal prior to forming a cloud

\footnotetext{
${ }^{1}$ School of Physics, Ryan Institute's Centre for Climate \& Air Pollution Studies, and MaREl@Galway, National University of Ireland Galway, University Road, Galway, Ireland. ${ }^{2}$ University of Wyoming Department of Atmospheric Science, Laramie, WY, USA. ${ }^{3}$ State Key Laboratory of Loess and Quaternary Geology and Key Laboratory of Aerosol Chemistry and Physics, Institute of Earth Environment, Chinese Academy of Sciences, Xi'an 710061, China. ${ }^{4}$ Center for Excellence in Quaternary Science and Global Change, Institute of Earth Environment, Chinese Academy of Sciences, Xi'an 710061, China. ${ }^{5}$ Department of Atmospheric and Oceanic Sciences, McGill University, Montreal, Quebec, Canada. ${ }^{\circledR}$ email: colin. odowd@nuigalway.ie
} 
in boundary layer circulation (i.e. what we call a cloud cycle) and only becomes bimodal after the first cloud cycle $e^{20}$. This is the case because nss- $\mathrm{SO}_{4}^{2-}$ aerosol formation via aqueous phase oxidation of dissolved $\mathrm{SO}_{2}$ in cloud drops is kinetically favoured over $\mathrm{SO}_{2}$ oxidation in haze droplets or in the gas phase or via homogenous production pathways ${ }^{20}$. This rapid oxidation pathway selectively increases the solute mass, and hence dry size, of the activated nuclei leading to a bimodal size distribution, separated by an intermodal minimum, with one mode representing non-activated particles and the other representing (previously) activated CCN. After the first cloud formation, successive non-precipitating cloud cycles further add solute mass to the active nuclei, acting to widen the intermodal separation ${ }^{20,21}$. Effectively, the number-size distribution holds key information on the number concentration of cloud droplets in a given cloud and combined with the $\mathrm{CCN} \mathrm{S}_{\mathrm{c}}-$ $D_{c}$ curve analysis enables us to determine the mean cloud peak supersaturation $\left(S_{\text {peak }}\right)$. Once the $S_{\text {peak }}$ is determined, the $D_{c}$ for each aerosol species can be approximated from a theoretical model of CCN activation and then the number concentration of activated cloud droplets from each species is determined (see methods), ultimately allowing quantification of the relative importance of nss-SO ${ }_{4}^{2-}$ and sea-salt to cloud droplet activation.

\section{RESULTS}

Southern Ocean aerosol measurements

The general properties of the submicron aerosol representative of the Austral summertime Southern Ocean region were reported in an earlier study ${ }^{19}$ where aerosol properties were classified in terms of air mass origin and subsequent advection. The area was dominated by maritime polar $(m P)$ and marine modified continental Antarctic ( $C A A)$ air masses (Supplementary Fig. 1). The $m P$ submicron aerosol was bimodal comprising a dominant Aitken mode with modal dry mobility diameter around $43 \mathrm{~nm}$ and an accumulation mode with modal dry mobility diameter of the order of $160 \mathrm{~nm}$. The $C A A$ aerosol also was bimodal with an Aitken mode also around $43 \mathrm{~nm}$ and a dominant accumulation mode centred around $120 \mathrm{~nm}$. The air mass average number concentrations were $387 \mathrm{~cm}^{-3}$ and $263 \mathrm{~cm}^{-3}$ for the $m P$ and $c A A$, respectively. The average refractory black carbon concentration was $1 \times 10^{-4} \mu \mathrm{g} \mathrm{m}^{-3}$ and $2 \times 10^{-4} \mu \mathrm{g} \mathrm{m}^{-3}$ for $\mathrm{mP}$ and $c A A$ aerosol, respectively, indicating the pristine nature of the air masses encountered.

Both air masses contained approximately the same average nss- $\mathrm{SO}_{4}^{2-}$ concentration, $0.4 \mu \mathrm{g} \mathrm{m}^{-3}$ and $0.37 \mu \mathrm{g} \mathrm{m}^{-3}$, respectively, while the $m P$ aerosol comprised 10 times more sea-salt than the $c A A$ aerosol $\left(0.3 \mathrm{\mu g} \mathrm{m}^{-3}\right.$ in $\mathrm{mP}$ and $0.03 \mu \mathrm{g} \mathrm{m}^{-3}$ in $\left.c A A\right)$. Ammonium was on average higher in the $\mathrm{mP}$ air $\left(0.09 \mu \mathrm{g} \mathrm{m}^{-3}\right)$ compared to $C A A$ air masses $\left(0.04 \mu \mathrm{g} \mathrm{m}^{-3}\right)$ and organic matter ranged from $0.07 \mathrm{\mu g} \mathrm{m}^{-3}$ in $\mathrm{mP}$ air to $0.02 \mathrm{\mu g} \mathrm{m}^{-3}$ in $c A A$ air (Supplementary Table 1). In essence, we had a simple marine aerosol system which comprised two basic inorganic chemical species-a partly neutralised $\mathrm{nss}^{-\mathrm{SO}_{4}^{2-}}$ aerosol and a sea-salt aerosol. Neither of the average air mass cases had sufficient contributions of organics to make any difference in water uptake processes (i.e. hygroscopic growth or cloud droplet activation). If we assume that the unspeciated organics, making up a volume fraction of $7 \%$ of the $M P$ case and $3 \%$ of the average $c A A$ case, are primary and the organic enrichment in sea-spray is negligible since you would need volume fractions greater than $55 \%$ to see noticeable effects on water uptake processes ${ }^{22}$. If we assume that the unspeciated organics are of secondary origin (combining the volume fraction with the chemically speciated methanesulfonic acid) then we see a volume fraction of $18 \%$ for both air masses, which is still very low to see water uptake effects ${ }^{14}$. To discern the sea-salt and nss- $\mathrm{SO}_{4}^{2-}$ size distributions, we applied a scaled seasalt flux distribution ${ }^{23}$ to measured aerosol particle size distributions, where the scaled sea-salt flux distribution was guided by bulk submicron chemical composition derived from the HR-ToF-AMS.

As presented in a related study ${ }^{19}$, we can regard the number concentration of cloud droplets, or the number concentration of activated $\mathrm{CCN}$, as the number of particles larger than the intermodal minimum, which has been shown to be reasonable from direct measurements of in-cloud and out-of-cloud aerosol $^{21,24}$. In doing so, we find that only $45 \%$ of the total measured particles were apparently activated in $M P$ air masses while $71 \%$ were apparently activated into cloud droplets in $C A A$ air masses, leading to a similar average CDNC in both air masses $\left(176 \mathrm{~cm}^{-3}\right.$ versus $187 \mathrm{~cm}^{-3}$, respectively). The major difference in aerosol chemistry between the two cases is the presence of sea-salt being significantly greater in the $m P$ air.

\section{$S_{c}-D_{c}$ curve analysis of Southern Ocean data}

To elucidate this significant difference in activation potential (e.g. particle size-dependent hygroscopicity and activation kinetics) of aerosol in the different air masses, we utilise measurements of $C C N$ activation through $S_{c}-D_{c}$ activation curves for the ambient cases (see methods) and we derive the characteristic aerosol critical supersaturation. This procedure is applied using the intermodal minimum as the $D_{c}$ of the mixed aerosol population and deriving $S_{\text {peak }}$ from the ambient $S_{c}-D_{c}$ activation curves (see methods). Once $S_{\text {peak }}$ is known, the $D_{c}$ for the sea-salt size distribution and $\mathrm{nss}^{-\mathrm{SO}_{4}^{2-}}$ size distribution, and the concentration of sea-salt based CDNC and nss-SO ${ }_{4}^{2-}$ CDNC could be extracted. Each aerosol species will activate at a slightly different $D_{c}$ based on its chemical properties and $\mathrm{S}_{\text {peak }}$. To determine the number of seasalt which activated $\left(\mathrm{CDNC}_{\mathrm{SS}}\right)$ and $\mathrm{nss}-\mathrm{SO}_{4}^{2-}$ which activated $\left(C_{S N} C_{S U L}\right)$, we summed up particles larger than the associated $D_{c}$ for theoretical sea-salt and sulfate activation at $S_{\text {peak }}$ calculated from the Aerosol Inorganic-Organic Mixtures Functional groups Activity Coefficients (AIOMFAC) model $^{25}$.

For the air mass average scenarios (Supplementary Fig. 2), the $C A A$ aerosol comprised a total nss- $\mathrm{SO}_{4}^{2-}$ particle population of $256 \mathrm{~cm}^{-3}$, six sea-salt particles $\mathrm{cm}^{-3}$, a $S_{\text {peak }}$ of $0.38 \%$ and a $D_{c}$ of $59 \mathrm{~nm}$, resulting in an activated cloud droplet concentration of $187 \mathrm{~cm}^{-3}$. Conversely, the $\mathrm{mP}$ aerosol comprised a total nss- $\mathrm{SO}_{4}^{2-}$ particle population of $362 \mathrm{~cm}^{-3}, 25$ sea-salt particles $\mathrm{cm}^{-3}$, a $S_{\text {peak }}$ of $0.24 \%$, and a $D_{c}$ of $71 \mathrm{~nm}$, resulting in an activated cloud droplet concentration of $176 \mathrm{~cm}^{-3}$. These results, along with each individual case making up the average, are compiled in Table 1. The data from all cases were statistically compared to clarify any connection between the critical parameters leading to the suppression of $\mathrm{nss}^{-\mathrm{SO}_{4}^{2-}}$ activation by sea-salt activation. We found that there was a high anti-correlation (Pearson correlation coefficient $r=-0.91, p<0.01$ ) between the activation of sea-salt and $S_{\text {peak }}$, followed in turn by a high anti-correlation $(r=-0.96$, $p<0.01$ ) between $D_{c}$ and $S_{\text {peak, }}$ ultimately leading to a high anticorrelation $(r=-0.96, p<0.01)$ between the percentage sulfate activated and $D_{c}$ (Fig. 1a). Despite inborn uncertainties from the calculation technique (see methods), the air mass data indicate a relationship between higher concentrations of sea-salt nuclei in a particle population rich in sulfate nuclei and the reduction of peak supersaturation.

\section{Microphysical modelling}

The experimental data suggest sea-salt strongly controls the activation of nss- $\mathrm{SO}_{4}^{2-}$ nuclei whereby the activated CDNC from nss- $\mathrm{SO}_{4}^{2-}$ nuclei can be reduced. Yet, the derivations of $S_{\text {peak }}$ and relative contributions of sea-salt and sulfate particles to total CDNC rely on a mixture of particle properties, assumptions, activation parameterisations, and the AIOMFAC model. To evaluate this mixed methodology and whether the observationderived experimental data could be reproduced in a theoretical 
Table 1. Calculated best central estimate values from ambient measurements are listed by air mass type ( $c A A$ or $m P$ ) chronologically and include the air mass averages (avg).

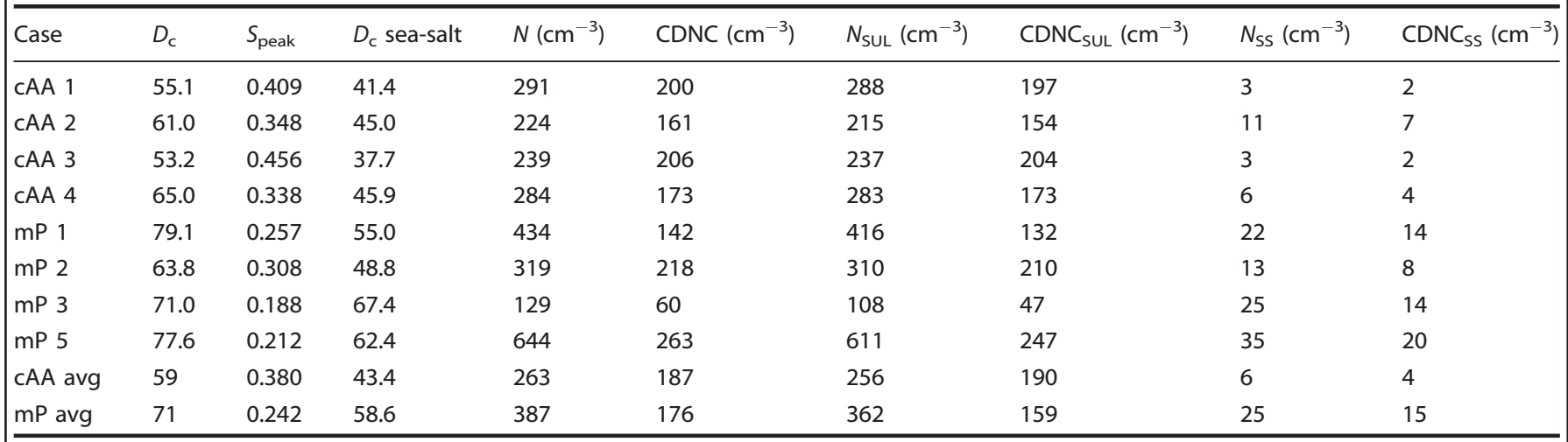

The number concentrations listed have a standard deviation of $2 \mathrm{~cm}^{-3}$. The aerosol critical dry mobility diameter of activation, taken as the intermodal minimum $\left(D_{c}\right)$ with an error of $\pm 5 \%$, was compared to ambient $C C N S_{c}-D_{c}$ slopes to find the cloud peak supersaturation ( $\left.S_{\text {peak }}\right)$ with an uncertainty of $\pm 0.02 \%$ supersaturation. This was then used in conjunction with the Aerosol Inorganic-Organic Mixtures Functional groups Activity Coefficients (AIOMFAC) mode ${ }^{25}$ for theoretically derived $\mathrm{NaCl} C \mathrm{CN} S_{c}-D_{c}$ curves to find the corresponding sea-salt activation diameter $\left(D_{c}\right.$ sea-salt). Total number (N), activated number (CDNC), and total and activated number concentrations of nss-SO ${ }_{4}^{2-}$ (SUL) and sea-salt (SS), respectively, are also listed. Number concentrations are best central estimates within an uncertainty of $\pm 8 \%$.
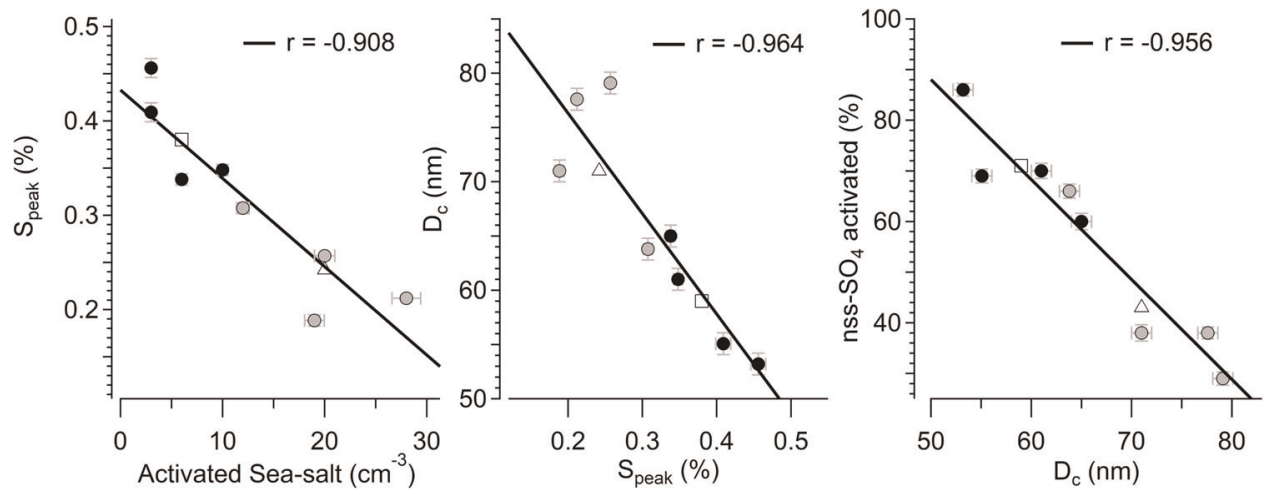

a

- $m P$ cases

- cAA cases

$\triangle m P$ average

$\square c A A$ average

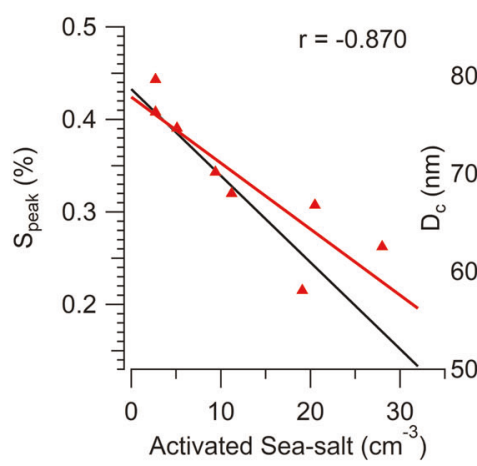

b
- cases Fit

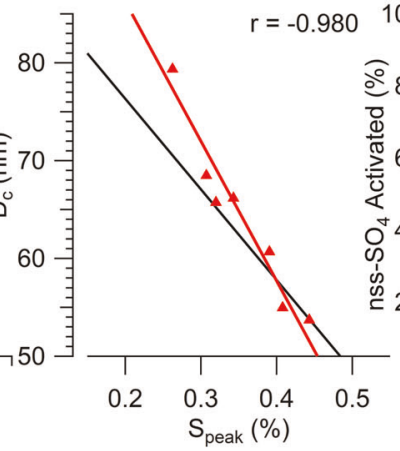

- Modelled cases

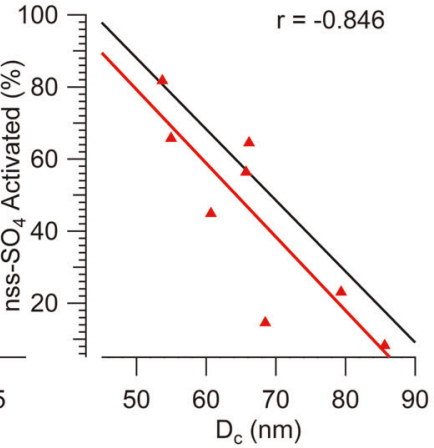

— Modelled Fit

Fig. 1 Comparison of cloud properties showing linear relatiosnhips in both observed data and subsequent parcel modelling. a Linear representation of the link between (Left) the cloud peak supersaturation ( $S_{\text {peak, }} \%$ ) and number concentration of sea-salt particles which activated into cloud droplets; (Middle) critical dry diameters $\left(D_{c}\right)$ and $S_{\text {peaki }}$ and (Right) the percentage of sulfate particles which activated into cloud droplets and $D_{c}$. The three linear representation give Pearson's $r$-values as indicated at the top of the graphs (all are significant for $p<$ 0.01 ). Each panel shows individual $m P$ cases as grey circles and $c A A$ cases as black circles, where error bars represent the uncertainty calculated for $S_{\text {peak, }} D_{c}$, and nss-SO $\mathrm{S}_{4}$ activated (see Methods). The open triangle $(m P)$ and open square $(c A A)$ shows the averaged case examples. b Parcel model simulations of experimental cases (red markers) with best fit line from model (red line) and experimental (black line) data. 
framework, we simulated each case using a simple adiabatic cloud parcel model with explicit microphysics (see methods). While we did not have the complete set of input data to replicate the environmental conditions exactly, we found that for realistic updrafts and assuming an initial monomodal $\mathrm{nss}^{-\mathrm{SO}_{4}^{2-}}$ size distribution with a modal diameter of $46-76 \mathrm{~nm}$, and a total number concentration equal to the sum of the sulfate contributions to the Aitken and accumulation modes (Supplementary Fig. $3)$, we could replicate the cloud-processed size distribution along with the suppression effect of sea-salt on supersaturation and nss- $\mathrm{SO}_{4}^{2-}$ activation, albeit with marginally more scatter in comparison to the experimental data (Fig. 1b).

Over the range of nss- $\mathrm{SO}_{4}^{2-}$ concentrations we encountered $\left(100-600 \mathrm{~cm}^{-3}\right)$, we found that with the addition of sea-salt nuclei to the lower sulfate concentration, with a vertical wind speed of $0.1 \mathrm{~m} \mathrm{~s}^{-1}$, total CDNC fell from 40 to $26 \mathrm{~cm}^{-3}$ while at the highest nss-SO ${ }_{4}^{2-}$ concentrations, total CDNC decreased from $160 \mathrm{~cm}^{-3}$ to about $28 \mathrm{~cm}^{-3}$ (Fig. 2). It should be noted that the model sensitivities also predict an inflection point for total CDNC at 50 nss- $\mathrm{SO}_{4}^{2-}$ particles $\mathrm{cm}^{-3}$ for $0.1 \mathrm{~m} \mathrm{~s}^{-1}$, where adding sea-salt actually increased CDNC. For the highest simulated updraft of $0.5 \mathrm{~m} \mathrm{~s}^{-1}$, the addition of sea-salt increased total CDNC from 80 to $130 \mathrm{~cm}^{-3}$ at the lower observed nss-SO ${ }_{4}^{2-}$, and decreased CDNC from 340 to $290 \mathrm{~cm}^{-3}$ at the higher observed nss- $\mathrm{SO}_{4}^{2-}$. The inflection point for CDNC at this updraft was $350 \mathrm{~cm}^{-3} \mathrm{nss}-\mathrm{SO}_{4}^{2-}$ particles (Fig. 2). The simulations reveal a strong and disproportionate control of sea-salt on the activation of nss- $\mathrm{SO}_{4}^{2-}$ nuclei whereby the activated $\mathrm{CDNC}$ from $\mathrm{nss}^{-} \mathrm{SO}_{4}^{2-}$ nuclei can be reduced, for example, in one scenario from 300 to $100 \mathrm{~cm}^{-3}$, through the addition of $30 \mathrm{~cm}^{-3}$ sea-salt nuclei.

We calculated the change in albedo from the change in CDNC over our simulations (Fig. 3). The change is calculated in reference to the baseline cloud albedo for $w=0.1 \mathrm{~m} \mathrm{~s}^{-1}$ and a sea-salt concentration of $1 \mathrm{~cm}^{-3}$. When $w<0.3 \mathrm{~m} \mathrm{~s}^{-1}$, adding sea-salt nuclei reduces the overall cloud albedo by as much as $30 \%$ for moderate nss- $\mathrm{SO}_{4}^{2-}$ particle concentrations in the range observed $\left(100-600 \mathrm{~cm}^{-3}\right)$. However, at higher $w$, increasing sea-salt nuclei leads to similar increases in albedo when $\mathrm{nss}^{-\mathrm{SO}_{4}^{2-}}$ particle concentrations are lower $\left(\sim 100 \mathrm{~cm}^{-3}\right)$ and leads to little change when nss-SO ${ }_{4}^{2-}$ particle concentrations are higher $\left(\sim 600 \mathrm{~cm}^{-3}\right)$. These microphysical effects propagate into changes in albedo by as much as $30 \%$, for moderate contributions of sea-salt.

This study identifies an important microphysical effect of seasalt during the cloud formation process in which sea-salt CCN can increase or decrease CDNC in marine boundary layer clouds depending on prevailing conditions and the abundance of secondary marine aerosol. This highlights that the role of seaspray in aerosol-cloud systems is more complex than originally
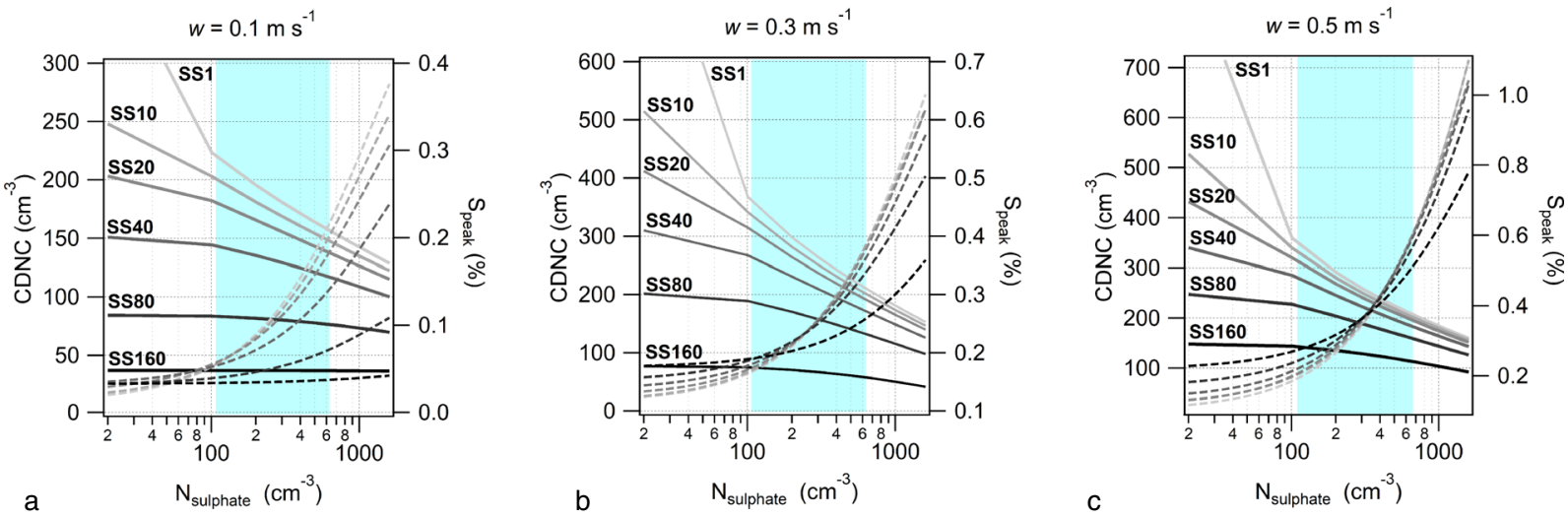

$\mathrm{T}=268.15 \mathrm{~K}$

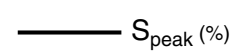

CDNC $\left(\mathrm{cm}^{-3}\right)$

Fig. 2 Sensitivity analysis of the cloud parcel model predictions to changing sea-salt number concentration (SS) and updraft velocity (w), depending on $\mathbf{n s s}-\mathrm{SO}_{4}$ concentration ( $\left.\boldsymbol{N}_{\text {sulfate }}\right)$. Left axis shows CDNC $\left(\mathrm{cm}^{-3}\right)$ in dashed lines while the right axis shows cloud peak supersaturation $\left(S_{\text {peak }} \%\right)$ in solid lines. All panels display sensitivity as a function of $N_{\text {sulfate }}$ in log-scale. All simulations were initialised at a parcel temperature of $268.15 \mathrm{~K}, 98.5 \%$ relative humidity, and $920 \mathrm{hPa}$. Different sea-salt particle number concentrations (SS) are indicated on the graph. Line shade indicates changes in SS (from 1 to 160 sea-salt particles $\mathrm{cm}^{-3}$ ) for $w=0.1 \mathrm{~m} \mathrm{~s}^{-1}(\mathbf{a}), w=0.3 \mathrm{~m} \mathrm{~s}^{-1}$ (b), and for $w=0.5 \mathrm{~m}$ $\mathrm{s}^{-1}$ (c). On all panels $(\mathbf{a}-\mathbf{c})$ the blue shaded region marks the range of $N_{\text {sulfate }}$ measured in the eight steady-state cases from the Southern Ocean study.
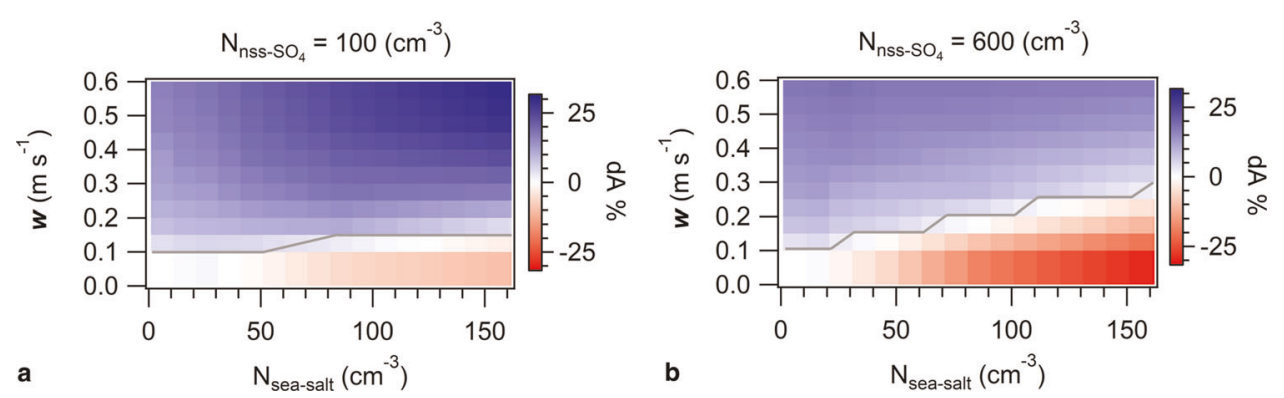

Fig. 3 Changes in cloud albedo (dA) as a function of updraft velocity $(w)$ and sea-salt aerosol concentration. The percent $\mathrm{dA}$ is calculated relative to the base case of $w=0.1 \mathrm{~m} \mathrm{~s}^{-1}$ and $N_{\text {sea-salt }}=1 \mathrm{~cm}^{-3}\left(A=0.31\right.$ for $N_{\text {ss-so4 }}=100 \mathrm{~cm}^{-3}$ and $A=0.41$ for $\left.N_{\text {ss-sO4 }}=600 \mathrm{~cm}^{-3}\right)$. If the albedo increases the $d A \%$ change is positive (blue), if albedo decreases the $d A \%$ is negative (red), as indicated by the diverging colour scale. The grey contour line shows $\mathrm{dA}=0 \%$. a A fixed nss-SO monomodal aerosol population of $100 \mathrm{~cm}^{-3}$ is simulated. $\mathbf{b} \mathrm{A}$ fixed nss-SO monomodal aerosol population of $600 \mathrm{~cm}^{-3}$ is simulated. 
thought and that sea-spray is a fundamentally important component of the marine aerosol climate system. In particular, the most significant impact of sea-salt CCN is not the direct contribution it makes to the CDNC but, indirectly, in how it can determine nss- $\mathrm{SO}_{4}^{2-} \mathrm{CCN}$ activation.

\section{METHODS}

Aerosol measurements

Submicron aerosol was measured during a campaign to the Southern Ocean from January-February 2015, with a suite of ship-borne in situ instrumentation. Non-refractory aerosol chemistry at sizes less than $1000 \mathrm{~nm}$ diameter was measured with an Aerodyne high-resolution time-of-flight aerosol mass spectrometer (HR-ToF-AMS); a TSI, Inc. scanning mobility particle sizer (SMPS) for aerosol particle dry mobility sizes from 20 to $500 \mathrm{~nm}$; a Droplet Measurement Technologies, Inc. single particle soot photometer (SP2) measuring black carbon, and a Droplet Measurement Technologies, Inc. manufactured CCN chamber (CCNC ${ }^{26}$ measuring sizesegregated CCN number concentration at varying supersaturation. The CCNC ran in a particle size-segregated set-up (see Paramonov et al. ${ }^{27}$ and Rose et $a{ }^{28}$ ) which utilised a differential mobility analyser (DMA) to separate out 10 different dry particle mobility diameters $\left(D_{\mathrm{m}}\right)$, log-spaced equally, ranging from 26 to $490 \mathrm{~nm}$. The DMA utilised $2 \mathrm{~L} \mathrm{~min}^{-1}$, which then was separated isokinetically between a butanol-based condensation particle counter (CPC) and further isokinetic split between the CCNC and a $0.5 \mathrm{~L} \mathrm{~min}^{-1}$ carrier flow (Supplementary Fig. 4). The CCNC then measured CCN concentrations at $0.08,0.29,0.47,0.82,1.48 \%$ supersaturation, which were resolved upon calibration as outlined by Rose et al. ${ }^{28}$. Standard HRToF-AMS transmission efficiency is $100 \%$ for particles in the aerodynamic diameter range $70-500 \mathrm{~nm}$, dropping gradually for smaller and large particles, with $\sim 50 \%$ transmission efficiency at $\sim 30 \mathrm{~nm}$ and $1000 \mathrm{~nm}^{29,30}$. More detailed information on instrumentation and calibration can be found in Fossum et al. ${ }^{19}$.

\section{$S_{c}-D_{c}$ activation curves}

Critical dry diameters $\left(D_{c}\right)$ for each critical supersaturation $\left(S_{c}\right)$ were resolved by plotting the fraction of activated $\mathrm{CCN}$ number to total condensation nuclei $(C N)$ number concentration $\left(N_{C C N} / N_{C N}\right)$ against the dry mobility diameter $\left(D_{\mathrm{m}}\right)$ and $D_{\mathrm{c}}$ was determined from the $D_{\mathrm{m}}$ at which $N_{\mathrm{CCN}} /$ $N_{C N}=0.5$. Taking each case's values for $S_{c}$ and plotting them against $D_{c}$ gives a critical dry diameter activation curve which should be linear in log-log space for a given chemical composition (following assumptions made in Petters and Kreidenweis ${ }^{31}$ ). The CCN activation efficiency curves used in this analysis result from the best linear fit to the $\log _{10}\left(S_{c}\right)$ vs. $\log _{10}\left(D_{c}\right)$ data. $S_{\text {peak }}$ is evaluated at the intermodal minimum using the ambient $S_{\mathrm{c}}-D_{\mathrm{c}}$ activation curves. The uncertainty of the CCN counter is $\pm 0.02 \%$ for $S_{\text {peak }}$ values. As the ambient CCN curve is based on the average size-dependent physico-chemical aerosol population properties, the $D_{c}$ for different chemical species at $S_{\text {peak }}$ may be different from the ambient. The model predictions for $\mathrm{CCN}$ activation curves of selected solutes in aqueous droplets were carried out by a combination of the AIOMFAC model ${ }^{25,32}$ and application of the Köhler equation ${ }^{33}$. The uncertainty in $S_{\text {peak }}$ is propagated to the chemical species-specific $D_{c}$, but because the non-linear relationship between $S_{c}$ and $D_{c}$ the uncertainty varies depending on both parameters. $D_{c}$ was found to range from 38 to $85 \mathrm{~nm}$ between different chemical species with an uncertainty ranging from \pm 0.7 to $9.4 \mathrm{~nm}$.

\section{Separation of sea-salt from nss-SO ${ }_{4}^{2-}$}

For the study dataset, sea-salt is considered here to be chemically represented by the theoretically derived $\mathrm{S}_{\mathrm{c}}-D_{\mathrm{c}}$ curve of $\mathrm{NaCl}$, and nss- $\mathrm{SO}_{4}^{2-}$ is chemically represented in accordance with the bulk molar degree of neutralisation. This simplification is reasonable based on the small fractions of organic mass (excluding methanesulfonic acid) in either average air mass case compared with the inorganic components, which may otherwise affect the hygroscopic properties of the aerosol. Using the number-size distributions of the aerosol, and the $D_{c}$ of sea-salt and nss- $\mathrm{SO}_{4}^{2-}$, respectively, the number contribution of the different aerosol types which would be considered activated into cloud droplets can be calculated using $S_{\text {peak }}$.

First, the SMPS data are constrained by fitting a sea-salt distribution from a North East Atlantic derived sea-spray source function ${ }^{23}$. This parameterisation is used for the Southern Ocean dataset in the absence of any multimodal sea-salt distribution parametrised from Southern Ocean data. Using a single spectral shape from a wind speed of $6.3 \mathrm{~m} \mathrm{~s}^{-1}$, which compared well with the measurements (average ship observed wind speed of the PEGASO cruise $\sim 7.5 \mathrm{~m} \mathrm{~s}^{-1}$ ), the distribution is scaled to better match observed sea-salt mass from the HR-ToF-AMS. This mass is assumed to represent a nascent pre-cloud cycling sea-salt distribution. The scaled seasalt distributions are subtracted from the overall number-size distributions with the remainder being assumed as the $\mathrm{nss}_{-} \mathrm{SO}_{4}^{2-}$ number contribution. Using the $D_{c}$ for either sea-salt or nss- $\mathrm{SO}_{4}^{2-}$, the number-size distributions are summed up for mobility diameters $>D_{c}$. The total activated number is similarly the sum of the number-size distribution for sizes $>$ intermodal minimum. The percent contribution is determined as the fraction of activated sea-salt or nss- $\mathrm{SO}_{4}^{2-}$ particles to total activated number. Outside of the intermodal minimum being a culmination of multiple cloud microprocesses, there is a $\pm 5 \%$ instrumentation error on the intermodal minimum value, which owes to the combination of a $\pm 10 \%$ uncertainty in the SMPS size-binning and subsequent lognormal fitting of the ambient data. As the contribution calculation stems from the intermodal minimum calculation and $S_{\text {peak }}$ value, the maximum deviation in $D_{c}$ or $S_{\text {peak }}$ from either uncertainty would only result in a $\pm 8 \%$ contribution change.

\section{Model description}

The 1-D Lagrangian parcel model used in this study calculates cloud particle activation using a hygroscopicity parameter, $\mathrm{k}$, from $\mathrm{k}$-Köhler theory ${ }^{31}$ to describe water activity of the aqueous droplet. The model uses a combination of Lagrangian microphysical equations for the formulation of droplet growth in a rising adiabatic parcel ${ }^{34}$, which accounts for the activation of particles while other coefficients involved in the diffusivity and thermal conductivity of water vapour follow the methods of AbdulRazzak and Ghan ${ }^{35}$. This model is written in Python, and is available as open source code called Pyrcel (http://github.com/darothen/pyrcel) ${ }^{36}$. All simulations through the model were run for the same initial parameters of parcel initial temperature $(T=273.15 \mathrm{~K}$ for $\mathrm{mP}$ and $T=268.15 \mathrm{~K}$ for $C A A)$, pressure $(P=920 \mathrm{hPa})$ and relative humidity $(\mathrm{RH}=98.5 \%)$. The $\mathrm{K}$ parameter for $\mathrm{nss}-\mathrm{SO}_{4}^{2-}$ was based on the molar degree of neutralisation $\left(\mathrm{DON}_{\mathrm{mol}}\right)$ of each case, and for sea-salt was 1.2. In the model, multimodal sea-spray distributions were used as input, the submicron modes derived from the source function found in Ovadnevaite et $\mathrm{al}^{23}$ and the supermicron mode described from a wind speed parameterisation ${ }^{37}$, both described in Supplementary Table 2. Input for a nss- $\mathrm{SO}_{4}^{2-}$ mode was reverse-engineered as Aitken monomodal distributions which would theoretically be produced in the marine environment from a single source (see supplementary material for a more detailed description of process and theory). These were different in each case with the reverse-engineered Aitken mode having a count median diameter ranging from 46 to $76 \mathrm{~nm}$.

Model sensitivity was tested for a range of environmental conditions including updraft velocity, cloud base temperature and pressure, and the location and amplitude of the initial lognormal nss- $\mathrm{SO}_{4}^{2-}$ and sea-salt particle number-size distributions (see supplementary material). The sensitivity study was evaluated by isolating and manipulating key variables to reveal single effects (see Fig. 2, and Supplementary Figs 6-8), and then testing compounding effects. Modelled cases for the different air mass types used case representative environmental conditions to achieve closure between activated and calculated CDNC and $S_{\text {peak. }}$

\section{DATA AVAILABILITY}

Data used in the paper and relevant to the conclusions are present in the paper and/ or the Supplementary Information. Further data concerning the PEGASO cruise can be found in Fossum et al. ${ }^{19}$, and/or references therein.

Received: 22 August 2019; Accepted: 26 February 2020; Published online: 08 April 2020

\section{REFERENCES}

1. Twomey, S. Pollution and the planetary albedo. Atmos. Environ. (1967) 8, 1251-1256 (1974).

2. Albrecht, B. A. Aerosols, cloud microphysics, and fractional cloudiness. Science 245, 1227 (1989)

3. Slingo, A. Sensitivity of the Earth's radiation budget to changes in low clouds. Nature 343, 49 (1990). 
4. Gryspeerdt, E., Quaas, J. \& Bellouin, N. Constraining the aerosol influence on cloud fraction. J. Geophys. Res.: Atmos. 121, 3566-3583 (2016).

5. Mulcahy, J. P. et al. Improved Aerosol Processes and Effective Radiative Forcing in HadGEM3 and UKESM1. J. Adv. Modeling Earth Syst. 10, 2786-2805 (2018).

6. Latham, J. \& Smith, M. H. Effect on global warming of wind-dependent aerosol generation at the ocean surface. Nature 347, 372-373 (1990).

7. Charlson, R. J., Lovelock, J. E., Andreae, M. O. \& Warren, S. G. Oceanic phytoplankton, atmospheric sulphur, cloud albedo and climate. Nature 326, 655-661 (1987).

8. Latham, J. et al. Marine cloud brightening. Philos. Trans. R. Soc. A: Math. Phys. Eng. Sci. 370, 4217-4262 (2012).

9. Salter, S., Sortino, G. \& Latham, J. Sea-going hardware for the cloud albedo method of reversing global warming. Philos. Trans. R. Soc. A: Math. Phys. Eng. Sci. 366, 3989-4006 (2008).

10. Bower, K., Choularton, T., Latham, J., Sahraei, J. \& Salter, S. Computational assessment of a proposed technique for global warming mitigation via albedoenhancement of marine stratocumulus clouds. Atmos. Res. 82, 328-336 (2006).

11. O'Dowd, C. D., Lowe, J. A. \& Smith, M. H. Coupling sea-salt and sulphate interactions and its impact on cloud droplet concentration predictions. Geophys. Res. Lett. 26, 1311-1314 (1999).

12. O'Dowd, C. D., Lowe, J. A., Smith, M. H. \& Kaye, A. D. The relative importance of non-sea-salt sulphate and sea-salt aerosol to the marine cloud condensation nuclei population: an improved multi-component aerosol-cloud droplet parametrization. Q. J. R. Meteorological Soc. 125, 1295-1313 (1999).

13. O'Dowd, C. D. et al. Biogenically driven organic contribution to marine aerosol. Nature 431, 676-680 (2004).

14. Ovadnevaite, J. et al. Surface tension prevails over solute effect in organicinfluenced cloud droplet activation. Nature 546, 637-641 (2017).

15. Ovadnevaite, J. et al. Primary marine organic aerosol: A dichotomy of low hygroscopicity and high CCN activity. Geophys. Res. Lett. 38, L21806 (2011).

16. Quinn, P. K., Coffman, D. J., Johnson, J. E., Upchurch, L. M. \& Bates, T. S. Small fraction of marine cloud condensation nuclei made up of sea spray aerosol. Nat. Geosci. 10, 674-679 (2017).

17. Hudson, J. G., Noble, S. \& Jha, V. Stratus cloud supersaturations. Geophys. Res. Lett. 37, https://doi.org/10.1029/2010GL045197 (2010).

18. Hudson, J. G. \& Da, X. Volatility and size of cloud condensation nuclei. J. Geophys. Res.: Atmos. 101, 4435-4442 (1996).

19. Fossum, K. N. et al. Summertime primary and secondary contributions to southern ocean cloud condensation nuclei. Sci. Rep. 8, 13844 (2018).

20. Hoppel, W. A., Frick, G. M. \& Larson, R. E. Effect of nonprecipitating clouds on the aerosol size distribution in the marine boundary layer. Geophys. Res. Lett. 13, 125-128 (1986).

21. Hudson, J. G., Noble, S. \& Tabor, S. Cloud supersaturations from CCN spectra Hoppel minima. J. Geophys. Res. D. Atmos. 120, 3436-3452 (2015).

22. Vaishya, A. et al. Bistable effect of organic enrichment on sea spray radiative properties. Geophys. Res. Lett. 40, 6395-6398 (2013).

23. Ovadnevaite, J. et al. A sea spray aerosol flux parameterization encapsulating wave state. Atmos. Chem. Phys. 14, 1837-1852 (2014).

24. Krüger, M. L. et al. Assessment of cloud supersaturation by size-resolved aerosol particle and cloud condensation nuclei (CCN) measurements. Atmos. Meas. Tech. 7, 2615-2629 (2014).

25. Zuend, A. et al. New and extended parameterization of the thermodynamic model AIOMFAC: calculation of activity coefficients for organic-inorganic mixtures containing carboxyl, hydroxyl, carbonyl, ether, ester, alkenyl, alkyl, and aromatic functional groups. Atmos. Chem. Phys. 11, 9155-9206 (2011).

26. Roberts, G. C. \& Nenes, A. A continuous-flow streamwise thermal-gradient CCN chamber for atmospheric measurements. Aerosol Sci. Technol. 39, 206-221 (2005).

27. Paramonov, M. et al. The analysis of size-segregated cloud condensation nuclei counter (CCNC) data and its implications for cloud droplet activation. Atmos. Chem. Phys. 13, 10285-10301 (2013).

28. Rose, D. et al. Calibration and measurement uncertainties of a continuous-flow cloud condensation nuclei counter (DMT-CCNC): CCN activation of ammonium sulfate and sodium chloride aerosol particles in theory and experiment. Atmos. Chem. Phys. 8, 1153-1179 (2008)

29. Canagaratna, M. R. et al. Chemical and microphysical characterization of ambient aerosols with the aerodyne aerosol mass spectrometer. Mass Spectrom. Rev. 26, 185-222 (2007).

30. Zhang, X. et al. Numerical characterization of particle beam collimation: Part II integrated aerodynamic-lens-nozzle system. Aerosol Sci. Technol. 38, 619-638 (2004).
31. Petters, M. D. \& Kreidenweis, S. M. A single parameter representation of hygroscopic growth and cloud condensation nucleus activity. Atmos. Chem. Phys. 7, 1961-1971 (2007).

32. Zuend, A., Marcolli, C., Luo, B. P. \& Peter, T. A thermodynamic model of mixed organic-inorganic aerosols to predict activity coefficients. Atmos. Chem. Phys. 8, 4559-4593 (2008).

33. Köhler, $\mathrm{H}$. The nucleus in and the growth of hygroscopic droplets. Trans. Faraday Soc. 32, 1152-1161 (1936).

34. Pruppacher, H. R. \& Klett, J. D. Microphysics of Clouds and Precipitation (Springer, 1978).

35. Abdul-Razzak, H. \& Ghan, S. J. A parameterization of aerosol activation: 2. Multiple aerosol types. J. Geophys. Res.: Atmos. 105, 6837-6844 (2000).

36. Rothenberg, D. \& Wang, C. Metamodeling of droplet activation for global climate models. J. Atmos. Sci. 73, 1255-1272 (2015).

37. O'Dowd, C. D., Smith, M. H., Consterdine, I. E. \& Lowe, J. A. Marine aerosol, sea-salt, and the marine sulphur cycle: a short review. Atmos. Environ. 31, 73-80 (1997).

\section{ACKNOWLEDGEMENTS}

The research leading to these results has received funding from SFI under MaREl; the European Union's Seventh Framework Programme (FP7/2007-2013) project BACCHUS under grant agreement $\mathrm{n} \_603445$; Spanish Ministry of Economy and Competitiveness (MINECO) as part of the PEGASO (Ref.: CTM2012-37615) and BIONUC (Ref: CGL2013-49020-R) projects. The Antarctic cruise that led to this study was organised by R. Simo and M. Dall'Osto from the Institut de Ciéncies del Mar (CSIC), Barcelona, Catalonia, Spain.

\section{AUTHOR CONTRIBUTIONS}

J.O. and D.C. collected all measurements used in this study during the cruise unless otherwise specified. A.Z. provided all theoretical data used in the analysis. J.P. and K.F. ran the model used in this study. J.S. and R.H. were consulted for their expertise during the writing of this paper. K.F. and C.O. wrote the paper, with contributions from J.O., D.C., J.P., R.H., A.Z. and J.S.

\section{COMPETING INTERESTS}

The authors declare no competing interests.

\section{ADDITIONAL INFORMATION}

Supplementary information is available for this paper at https://doi.org/10.1038/ s41612-020-0116-2.

Correspondence and requests for materials should be addressed to C.O.

Reprints and permission information is available at http://www.nature.com/ reprints

Publisher's note Springer Nature remains neutral with regard to jurisdictional claims in published maps and institutional affiliations.

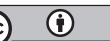

Open Access This article is licensed under a Creative Commons Attribution 4.0 International License, which permits use, sharing, adaptation, distribution and reproduction in any medium or format, as long as you give appropriate credit to the original author(s) and the source, provide a link to the Creative Commons license, and indicate if changes were made. The images or other third party material in this article are included in the article's Creative Commons license, unless indicated otherwise in a credit line to the material. If material is not included in the article's Creative Commons license and your intended use is not permitted by statutory regulation or exceeds the permitted use, you will need to obtain permission directly from the copyright holder. To view a copy of this license, visit http://creativecommons. org/licenses/by/4.0/.

(c) The Author(s) 2020 